\title{
Methylated Taurines and Choline Sulphate in Red Algae
}

\author{
B ENGT L I N D B E R G
}

\author{
Organisk-kemiska Institutionen, Kungl. Tekniska Högskolan, Stockholm, Sweden
}

\begin{abstract}
Taurine, N-methyltaurine, di-N-methyltaurine and choline sulphate have been isolated from red algae. From these results a metabolic pathway from taurine via $\mathrm{N}$-methylated taurines and choline sulphate to polysaccharide sulphate esters might be indicated.
\end{abstract}

$\mathrm{D}_{\mathrm{r} \text { tat }}$ uring an investigation of the low-molecular weight carbohydrates of the red alga Furcellaria fastigiata, a substance which proved to be di-N-methyltaurine was isolated $\mathbf{1}$. The crude product, free from carbohydrates, was difficult to purify by crystallisation, suggesting that it was contaminated by substances of similar structure.

By a similar procedure, taurine has now been isolated from Ptilota pectinata and Porphyra umbilicalis. This observation was followed by a more systematic search for similar compounds in red algae. The three $\mathrm{N}$-methylated taurines were prepared and a method to separate and characterise them by paper chromatography was developed. Taurine, N-methyltaurine and di-N-methyltaurine could be detected with an indicator reagent, bromothymol blue, previously used for the detection of ammonium salts of fatty acids ${ }^{2}$. The spots, yellow on a blue background, faded rapidly and the two first substances were preferably detected with the ninhydrin reagent. The colour reaction of $\mathrm{N}$-methyltaurine was not as sensitive as that of taurine and a higher temperature was required to produce the colour. Tri-N-methyltaurine could not be detected by these reagents. The first three substances could be separated in a number of solvent systems of which ac tone-water $(9: 1)$ proved quite convenient. As expected, taurine had the lowest and di-N-methyltaurine the highest $R_{F}$-value.

The red alga Gelidium cartilagineum, the principal agar weed used on the American west coast, was especially rich in these substances, containing about $1.5 \%$ of internal salts. Evidence for the presence of taurine, N-methyltaurine and di-N-methyltaurine was obtained by paper chromatography, and the last two were also isolated and proved to be identical with the corresponding authentic materials (mixed melting points). For the attempted isolation of tri-N-methyltaurine, a fraction of internal salts free from carbohydrates, was filtered through a column of Dowex 2 in the $\mathrm{OH}$-state. Tri-N-methyltaurine, being an internal salt of a strong base and a strong acid, would not be expected

Acta Chem. Scand. 9 (1955) No. 8 
to be absorbed in contrast to the others, which are internal salts of a weak base and a strong acid. A substance was isolated which, most unexpectedly, was not tri-N-methyltaurine but was recognised as choline sulphate by its I.R. absorption spectrum. The mother liquors from the choline sulphate were treated with $5 \mathrm{~N}$ hydrochloric acid at $100^{\circ}$ overnight, and the solution was deionised and concentrated. No tri- $\mathrm{N}$-methyltaurine could be detected in the minute residue. The presence of small amounts of tri- $\mathrm{N}$-methyltaurine is, however, not excluded by these experiments, as it might have accumulated in other fractions.

$\mathrm{N}$-Methyltaurine and di-N-methyltaurine have not been found in Nature before, while taurine itself is known to occur in the muscular tissue of invertebrates and also in vertebrates as a constituent of the bile acids. Unfortunately a lot of diatoms grow on the alga investigated. Most of these were removed prior to the extraction but the complete exclusion of them was practically impossible. A small amount of mytilitol (0.002\%) was isolated from the extract, and this C-methylinositol, previously isolated from the edible mussel, Mytilus edulis ${ }^{3}$, probably comes from invertebrates in the sample extracted. The percentage of the taurines, however, is so high that it seems to exclude the possibility that these compounds are derived from impurities in the plant material.

Choline sulphate has been isolated from an Aspergillus ${ }^{4}$ and a Penicillium $^{5}$ mould and from lichens of the family Roccella ${ }^{6}$. The isolation of this substance from a red alga is of special interest, as red algae contain a high percentage of galactosan sulphate esters (agar), and it seems reasonable to put forward the hypothesis that the sulphate ester groups are transferred from choline to the polysaccharide by a transesterification. The simultaneous occurrence of choline sulphate and the taurines might indicate a biochemical relationship between these substances, e.g. that taurine is successively methylated to tri-N-methyltaurine, which is then, by some sort of oxidation, transferred into choline sulphate.

$$
\mathrm{H}_{3} \stackrel{+}{\mathrm{N}} \mathrm{CH}_{2} \mathrm{CH}_{2} \mathrm{SO}_{3} \longrightarrow\left(\mathrm{CH}_{3}\right)_{3} \stackrel{+}{\mathrm{N}} \mathrm{CH}_{2} \mathrm{CH}_{2} \mathrm{SO}_{3} \stackrel{?}{\longrightarrow}\left(\mathrm{CH}_{3}\right)_{2} \stackrel{+}{\mathrm{N}} \mathrm{CH}_{2} \mathrm{CH}_{2} \mathrm{OSO}_{3}
$$

\section{EXPERIMENTAL}

(Melting points uncorrected)

Ptilota pectinata. The alga ( $130 \mathrm{~g})$ was extracted with ether for 2 days and with methanol for 14 days. The methanol extract was concentrated to dryness, the residue treated with water, filtered and the aqueous phase deionised with IR 120 and IR4B and concentrated. The sirup ( $1.1 \mathrm{~g}$ ) was dissolved in hot aqueous ethanol and on cooling crystals $(170 \mathrm{mg}$ ) separated. By paper chromatography the presence of taurine and small amounts of $N$-methyltaurine was demonstrated, and by further crystallisation pure taurine, m.p. $320-325^{\circ}$ (decomp.) was obtained (Found: C 19.1; H 5.60. Calc. for $\mathrm{C}_{2} \mathrm{H}_{7} \mathrm{O}, \mathrm{NS}: \mathrm{C} 19.2$; $\mathrm{H}$ 5.64.)

Porphyra umbilicalis. The isolation of an "internal salt" fraction from this alga has been reported in a previous communication ". It melted at $300-315^{\circ}$ (decomp.) and gave a strong spot corresponding to taurine and a faint spot corresponding to $\mathrm{N}$-methyltaurine.

Gelidium cartilagineum. The alga $(370 \mathrm{~g})$ was extracted and worked up as described above for Ptilota pectinata. The crystals obtained from the sirup were recrystallised four times from aqueous ethanol yielding a fraction, $\mathrm{G}_{1}(2.1 \mathrm{~g})$ which was free from carbo- 
hydrates and melted at $270-280^{\circ}$ (slight decomp.). The last three mother liquors were concentrated yielding another carbohydrate free fraction, $G_{2}(2.1 \mathrm{~g})$. The remaining mother liquors were combined, yielding $\mathrm{G}_{3}(14.0 \mathrm{~g})$.

$G_{3}$ was fractionated on a carbon column using the gradient elution technics as previously described ${ }^{1}$. Floridoside $(6.3 \mathrm{~g})$, m.p. $127-128^{\circ}$, was isolated from some of the last fractions. The early fractions, containing internal salts, glycerol and cyclitols were concentrated and filtered through a column of Dowex 2 in the $\mathrm{OH}^{-}$state and the column washed with water. The eluate, which had an odour of trimethylamine, contained the carbohydrates and when it was concentrated a small quantity of crystalline material (8 mg), m.p. $258-262^{\circ}$, separated. The substance was chromatographically indistinguishable from mytilitol and the m.p. was undepressed on admixture with this substance. The mother liquors were concentrated to a sirup (0.37 g) in which the presence of glycerol, mesoinositol and laminitol was demonstrated by paper chromatography. Any choline sulphate or tri-N-methyltaurine present in $\mathrm{G}_{3}$ should be accumulated in this fraction. The column was then eluted with $2 \mathrm{~N}$ acetic acid $(100 \mathrm{ml})$ and the eluate concentrated yielding crystalline material (1.35 g) which, by chromatographic evidence, consisted of a mixture of taurine, $\mathrm{N}$-methyltaurine and di-N-methyltaurine. Part of this fraction $(200 \mathrm{mg}$ ) was fractionated on thick filter paper (Whatman $3 \mathrm{MM}$ ) using as solvent acetonewater (19: 1). Chromatographically pure $\mathrm{N}$-methyltaurine $(60 \mathrm{mg})$ was isolated by this procedure. After two crystallisations from aqueous ethanol the substance (34 mg) melted at $240-242^{\circ}$, undepressed on admixture with an authentic specimen.

Pure di-N-methyltaurine (70 mg) melting at $297-300^{\circ}$ (decomp.) after one crystallisation was also isolated. Taurine was present only in small quantities and was obtained in a small fraction (11 mg) consisting of about equal parts of taurine and $\mathrm{N}$-methyltaurine.

Fractionation of $\mathrm{G}_{2}$ on a carbon column was attempted but was not very successful. The chief constituent of the fraction was di-N-methyltaurine, which was the only substance isolated in a pure state.

$\mathrm{G}_{1}(1.8 \mathrm{~g})$ was dissolved in water and filtered through a column $(50 \mathrm{ml})$ of Dowex 2 in the $\mathrm{OH}^{-}$state and the column washed with water $(300 \mathrm{ml})$. The aqueous solution was concentrated to dryness and the residue $(0.54 \mathrm{~g})$ recrystallised twice from aqueous ethanol. The crystals $(290 \mathrm{mg})$ on heating decomposed at about $315^{\circ}$ without melting while tri-N-methyltaurine melts with decomposition at about $335^{\circ}$. The behaviour on heating was the same as that of choline sulphate and the I.R. absorption spectra of the two substances were identical.

The Dowex 2 column was eluted with $2 \mathrm{~N}$ acetic acid (150 ml) yielding crystals $(1.18 \mathrm{~g})$. By crystallisation from aqueous ethanol, pure di-N-methyltaurine, m.p. 300-302 (decomp.) was obtained.

Synthesis of methylated taurines. Sodium 2-bromoethane-sulphonate $(11 \mathrm{~g})$ was dissolved in a strong (25-33\%) aqueous solution $(700 \mathrm{ml})$ of the amine $\left[\mathrm{NH}_{2} \mathrm{CH}_{3}, \mathrm{NH}\left(\mathrm{CH}_{8}\right)_{2}\right.$ and $\mathrm{N}\left(\mathrm{CH}_{3}\right)_{3}$, resp.], and kept at room temperature for 10-14 days. The solution was then concentrated to dryness under reduced pressure, dissolved in water, deionised by filtering through columns of IR 120 and IR 4B, concentrated and crystallised from aqueous ethanol. The method is essentially the same as previously used for these substances, improved, however, by the use of ion exchange resins to remove the salts.

$$
\begin{array}{lll}
\text { N-Methyltaurine } & \text { Yield } 76 \% & \text { M.p. 244-245 } \\
\text { Di-N-methyltaurine Yield } 68 \% & \text { M.p. 299-304 } \\
\text { Tri-N-methyltaurine Yield } 75 \% & \text { M.p. 335-340 (decomp.) }
\end{array}
$$

Acknowledgements. The author is indebted to Statens Naturvetenskapliga Forsloningsråd for financial support, to Fil.lic. K. E. Almin, Stockholm, for the infrared absorption spectra and to Ing. L. Mikiver for his skilful assistance. The algae were kindly supplied by Institutt for Tang- og Tare-forskning, Trondheim, Dr. Colm O'h Eocha, University of California, and Mr. H. H. Selby, American Agar and Chemical Co, San Diego, California. 


\section{REFERENCES}

1. Lindberg, B. Acta Chem. Scand. 9 (1955) 1087.

2. Brown, F. Biochem. J. London 47 (1950) 598.

3. Ackerman, D. Ber. 54 (1921) 1938.

4. Wooley, D. W. and Petersen, W. H. J. Biol. Chem. 122 (1937) 213.

5. de Flines, J. J. Am. Chem. Soc. 77 (1955) 1676.

6. Lindberg, B. Acta Chem. Scand. 9 (1955) 917.

7. Lindberg, B. Acta Chem. Scand. 9 (1955) 1091

8. Lindberg, B. and McPherson, J. Acta Chem. Scand. 8 (1954) 1875.

Received June 16, 1955. 